\title{
Community organizations' perspectives on the impact of a nursing student-led academic-community partnership program
}

\author{
Sydney Hausman-Cohen, Nali Asamoah, Christina Yee, Isabel Braun, Morgan Shick, Amani Abdallah, Jennifer Morone*, \\ Terri Lipman \\ School of Nursing, University of Pennsylvania, United States
}

Received: January 13, 2020

Accepted: April 12, 2020

Online Published: April 23, 2020

DOI: $10.5430 /$ jnep.v10n8p9

URL: https://doi.org/10.5430/jnep.v10n8p9

\begin{abstract}
Academic-community partnerships can have a direct positive impact on community partners and university students. Community Champions, a student-led program, promotes local outreach and engagement with a variety of community initiatives. The purpose of this study was to assess community partners' perceptions of the Community Champions program to better support the goals of the community and to complement prior research evaluating the impact of the Community Champions program on university students. The study used a 27-item survey, consisting of 20 Likert-scale items and seven open-ended questions. Eighteen community partners were invited via email to complete the online survey. Quantitative responses were analyzed using descriptive statistics, and qualitative responses were reviewed for themes to generate future recommendations. Fourteen of the eighteen community organizations responded to the survey (78\% response rate). Assessment of community partners' perspectives were synthesized across four themes: motivations, benefits, challenges, and general satisfaction. Community partners indicated that sharing labor and resources to enhance community health goals were key factors in creating mutually beneficial partnerships. Building effective academic-community partnerships is essential to increasing student engagement, while also addressing priorities of community organizations. Academic student programs that engage the community can positively impact both the community partners and university students.
\end{abstract}

Key Words: Academic-Community partnerships, Community engagement, Nursing education

\section{INTRODUCTION}

Academic-community partnerships connect engaged volunteers, funding, educational resources, and innovative minds from colleges and universities with interested organizations in their neighboring communities. Research suggests benefits are derived from these collaborations, for both the communities and those who volunteer at these community sites. A qualitative study involving 99 community partners describe the direct positive impact of service learning on both academic and community partners by increasing the organiza- tional capacity and initiatives of outreach programs, strengthening the relationship between communities and their neighboring universities, and presenting students with opportunities for self-reflection as well as reinforcing intrinsic motivation to sustain future community relationships. ${ }^{[1]}$ However, participating community members' perceptions of these partnerships are rarely surveyed and analyzed.

A successful community partnership includes the collaboration of the community and its volunteers through regular,

*Correspondence: Jennifer Morone; Email: jcroc@ @ursing.upenn.edu; Address: School of Nursing, University of Pennsylvania, United States. 
frequent communication, trust and respect, and joint leadership. ${ }^{[2]}$ It is the responsibility of the university to assess the perspectives of the communities with whom it engages. Community assessments provide crucial opportunities to strengthen the foundation of the academic-community partnerships.

A study of eight academic-community partnerships found that universities often fail to recognize the particular perspectives and knowledge that communities possess regarding their own neighborhoods. ${ }^{[3]}$ It is critical that community members express their own ideas for neighborhood enhancement and subsequently obtain the necessary resources from the partnering university. The chronology in which these events occur is essential; these goals must only be formulated after needs and priorities are expressed by the community partners.

Although community engagement has been shown to be mutually beneficial for all involved, the partnerships are not without drawbacks. Some community partnerships cite shortterm involvement and communication barriers when noting some of the challenges with working with student volunteers. ${ }^{[4]}$ However, other studies have demonstrated benefits to both parties. Data from a large sample of nonprofit managers suggested that students often participated beyond their initial commitments and increased community organizations visibility across university campuses. ${ }^{[5]}$ Many community organizations are in need of resources and human capital. ${ }^{[6]}$ Specifically, a study that explored the motivations and barriers to community partnerships demonstrated that a number of community organizations found that students fostered valuable connections to resources that the universities could provide to the communities. ${ }^{[7]}$ Finally, as the relationship of these partnerships is complex and dynamic, the necessity of ongoing assessment and evaluation is imperative. Therefore, sustainability, preferences, and types of services provided should be frequently assessed by all partners involved. ${ }^{[8]}$

The University of Pennsylvania's School of Nursing Community Champions (NCC) program facilitates outreach programs with various communities in Philadelphia. Nursing students form partnerships with the community sites, maintain relationships with community members, and initiate projects cultivated from the expressed needs of community collaborators. Perspectives of nursing students involved in the Community Champions program have previously been surveyed; students expressed that "it was important to apply what they were learning in the classroom to the surrounding community". ${ }^{[9]}$ This study builds upon this prior research by evaluating the efficacy and impact of the Community Champions program from the viewpoints of the community partners in the greater Philadelphia neighborhoods. The purpose of this research was to assess the community's perception of the Community Champions program, as it relates to perceived motivating factors, benefits, challenges and general satisfaction, to better support the goals and priorities of the community partners.

\section{METHODS}

\subsection{Survey development}

The data for this study was collected from a 27 -item online survey, consisting of 20 Likert-scale items and seven open-ended questions. The survey was developed based on a review of 16 studies and examined evaluations of academiccommunity partnerships. The literature review identified six unique interview guides and four unique surveys. Two interview guides and two surveys were selected and synthesized for development of the project survey instrument. ${ }^{[5,7,10,11]}$ Questions from these four research instruments were first organized thematically, revealing four major themes relevant to the academic-community partnership: motivations, benefits, challenges, and general satisfaction. The research team then selected four to five rating scale questions and one to two open-ended question from the existing compilation of questions within each thematic area, as well as one demographic question also derived from the literature. The final synthesized survey utilized in this study included a total of 20 rating scale questions and seven open-ended questions organized into the themes of motivation (six questions), benefits (seven questions), challenges (seven questions), general satisfaction (six questions), and demographics (one question). Responses to rating scale questions were graded on five-point scales, depending on level of importance, agreement, and likelihood.

\subsection{The sample}

Primary site contacts from each of the 18 community organizations participating in the NCC program were invited via email to participate in the study. The participating organizations provided a diverse array of services to the local intercity population, including after school tutoring, STEM (science, technology, engineering and mathematics) and health education, infant and women's health, fitness classes, and health screenings.

\subsection{Analysis}

Data from the completed surveys were downloaded and analyzed using Microsoft Excel. Quantitative responses were evaluated using descriptive statistics. Due to the small sample size and limited number of responses to open-ended questions, primary results were collected based on quantitative responses, while qualitative responses were primarily utilized to generate recommendations. 


\section{RESUltS}

Fourteen of eighteen community partner organizations contacted responded to the survey, yielding a response rate of $78 \%$. Survey respondents represented the following fields: elementary education, high school education, infant health, women's health, older adult health, mental health, community fitness, and literacy. The survey analysis was organized according to four categories: motivation for working with students, perceived benefits of academic-community partnerships, challenges with academic-community partnerships and general satisfaction with the partnership.

\subsection{Motivations}

The first section of the survey sought to identify factors that motivated community partners to participate in the NCC program. Five Likert-scale questions asked respondents to rank the extent to which five factors motivated their decision to participate in the academic-community partnership; additional motivating factors were elicited via one open-ended question. The majority of the respondents indicated that each of the listed motivating factors played some role in their decision to work with student volunteers from the NCC program (see Figure 1). Approximately $93 \%(n=13)$ of respondents indicated that "educating nursing students about [their] community" and "working with volunteers is part of [their] organization's mission" were either important or very important in their decision to work with NCC volunteers. Similarly, $86 \%(n=12)$ reported that building their relationship with the university was an important or very important motivating factor. Of notable interest, one respondent commented, "We found that what was more important than OUR relationship with the university, was its relationship with our client/community-based members." Finally, 79\% $(n=11)$ of respondents indicated that the ability of nursing students to "help improve existing health-related services" was either an important or very important motivating factor. One education-based program described, "A lot of our [high school] students showed interest in working in the healthcare field. I thought it would be great for them to interact with [college] students going into that field and also be immersed in the topics they study in school. The nursing students have been great with giving the students information on health issues that impact their community and they have learned so much."

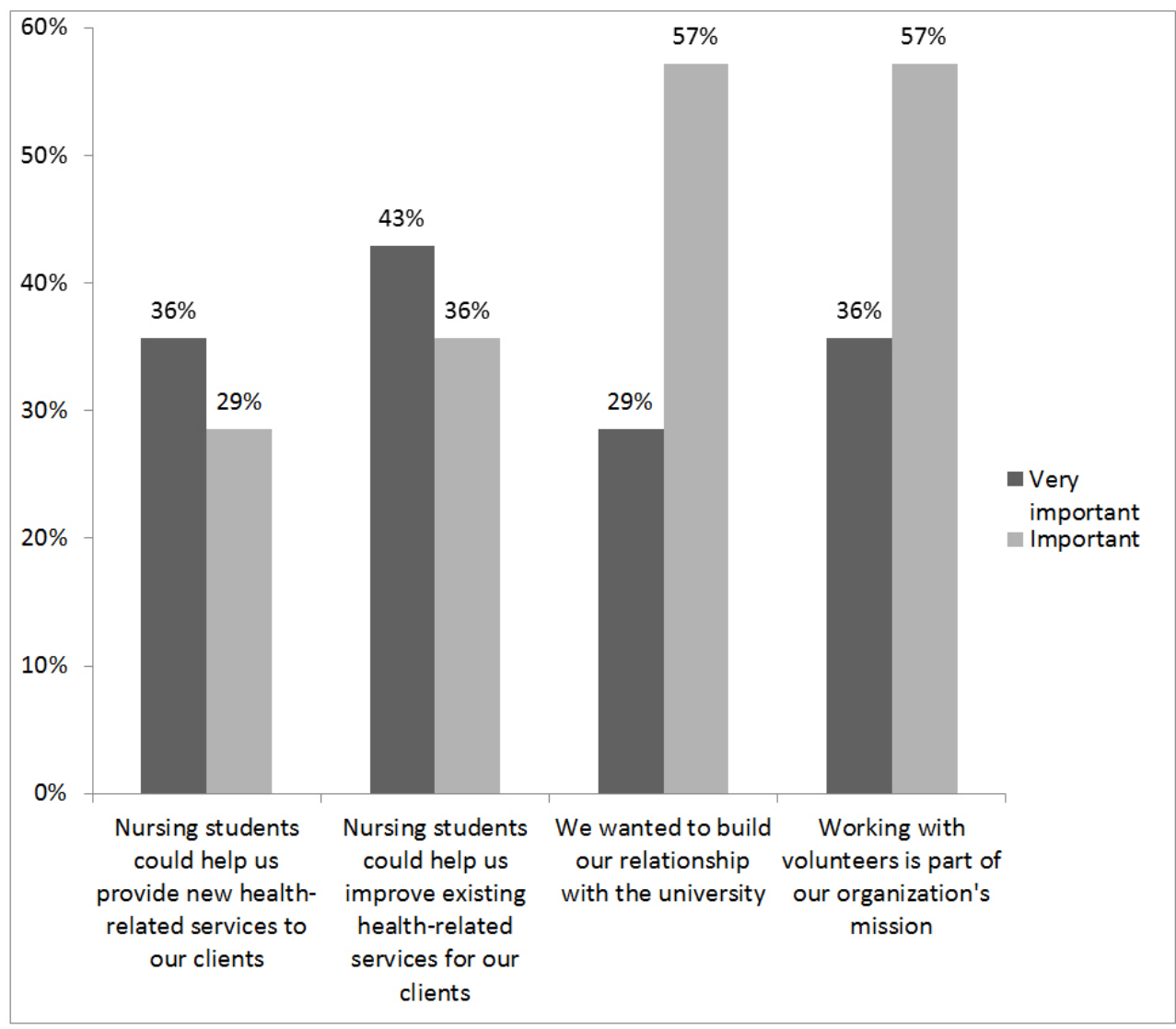

Figure 1. Motivating factors for participation in the academic-community partnership program. Responses to questions of "How important were each of the following in your decision to work with student volunteers?" $\mathrm{n}=14$ NCC partner organizations 


\subsection{Benefits}

The second section of the survey, consisting of five Likertscale questions and two open-ended questions, addressed benefits of the academic-community partnership for community participants. Nearly all respondents $(93 \%, \mathrm{n}=13)$ reported that participating in an academic community partnership program benefited their community by strengthening its relationship with the University (see Table 1). A majority of respondents $(70 \%, \mathrm{n}=10)$ indicated that participation in the NCC program allowed them to provide new health-related services to their clients/community members, while $61 \%$ (n $=8.5$ ) indicated that the partnership increased the number of community members engaged with their program. One participant explained that nursing student volunteers, "provide[d] career exploration experiences with our program's seventh grade students, helping them build the skills they need for a successful future." Another participant expressed that they "provided confidence, courage and the importance of understanding confidentiality to the community-based client."

Table 1. Benefits of participation in the academic-community partnership program

\begin{tabular}{|c|c|c|c|c|c|}
\hline $\begin{array}{l}\text { "Please rank your agreement/disagreement with the } \\
\text { following ways in which the NCC program may have } \\
\text { impacted your organization." }\end{array}$ & $\begin{array}{l}\text { Strongly } \\
\text { agree }\end{array}$ & Agree & $\begin{array}{l}\text { Neither agree } \\
\text { nor disagree }\end{array}$ & Disagree & $\begin{array}{l}\text { Strongly } \\
\text { disagree }\end{array}$ \\
\hline Strengthened our community's relationship with the university & $31 \%$ & $62 \%$ & $7 \%$ & $0 \%$ & $0 \%$ \\
\hline $\begin{array}{l}\text { Provided new health-related services to our clients/community } \\
\text { members }\end{array}$ & $8 \%$ & $62 \%$ & $15 \%$ & $15 \%$ & $0 \%$ \\
\hline $\begin{array}{l}\text { Increased the number of community members engaged with our } \\
\text { program }\end{array}$ & $23 \%$ & $38 \%$ & $31 \%$ & $8 \%$ & $0 \%$ \\
\hline $\begin{array}{l}\text { Improved existing health-related services for our } \\
\text { clients/community members }\end{array}$ & $0 \%$ & $54 \%$ & $31 \%$ & $15 \%$ & $0 \%$ \\
\hline
\end{tabular}

\subsection{Challenges}

In the third section of the survey, consisting of six Likertscale items and one open-ended question, respondents identified key challenges of participation in the Community Champions program. Respondents most frequently indicated that a significant challenge of participating in the NCC program was the time constraints of students. Thirty-eight percent of respondents $(\mathrm{n}=5)$ indicated that student volunteers' time constraints posed a very great or great challenge to working with the NCC program (see Table 2). Twenty-one percent (n $=3$ ) indicated that time constraints of staff and variations in priorities between the organization and students posed a great or very great challenge to participation in the program. One respondent stated, "The biggest challenge we face is finding nursing students who can make the volunteer commitment."
Another expressed that their main challenge was students' changing schedules, reflecting, "Not all training [is] done at the same time, so a lot of effort [is required] on the organization's end." One organization recognized that a stronger student commitment was necessary for the success of the program, stating, "For next semester, we will be asking for a two day [per week] minimum requirement for this program in order to best support our students and to promote as much consistency as possible among and within our teams. I know that this may make it difficult for students to participate due to classes and clinicals. We will also be changing the orientation structure a bit to continuing deepening and improving it - we may make use of a weekend format to allow for me time and for more in-depth on-boarding."

Table 2. Challenges

\begin{tabular}{|c|c|c|c|c|c|}
\hline $\begin{array}{l}\text { Please rank the following challenges you faced } \\
\text { when working with the NCC program. }\end{array}$ & $\begin{array}{l}\text { To a very great } \\
\text { extent }\end{array}$ & $\begin{array}{l}\text { To a great } \\
\text { extent }\end{array}$ & $\begin{array}{l}\text { To some } \\
\text { extent }\end{array}$ & $\begin{array}{l}\text { To a small } \\
\text { extent }\end{array}$ & Not at all \\
\hline $\begin{array}{l}\text { Time constraints of our staff to supervise/train } \\
\text { student volunteers }\end{array}$ & $7 \%$ & $14 \%$ & $29 \%$ & $14 \%$ & $36 \%$ \\
\hline Time constraints of student volunteers & $15 \%$ & $23 \%$ & $38 \%$ & $9 \%$ & $15 \%$ \\
\hline Lack of facilities, funding, or space & $0 \%$ & $14 \%$ & $21 \%$ & $36 \%$ & $29 \%$ \\
\hline Organization priorities differ from student priorities & $0 \%$ & $21 \%$ & $29 \%$ & $21 \%$ & $29 \%$ \\
\hline Lack of communication from student volunteers & $0 \%$ & $7 \%$ & $29 \%$ & $14 \%$ & $50 \%$ \\
\hline $\begin{array}{l}\text { Student volunteers are inadequately } \\
\text { trained/prepared }\end{array}$ & $0 \%$ & $7 \%$ & $8 \%$ & $14 \%$ & $71 \%$ \\
\hline
\end{tabular}

Note. $n=14$ respondents from NCC partner organizations 


\subsection{General satisfaction}

The final section of the survey, consisting of four Likertscale questions and two open-ended questions, collected data on community organizations' general satisfaction with their partnership with the Community Champions program. More than $75 \%(\mathrm{n}=11)$ of respondents indicated that the part- nership with NCC had a positive impact in the community and was useful to their organization, easy to manage, and worthwhile to continue (see Figure 2). Of these responses, respondents were most emphatic about continuing the partnership, with $62 \%$ of respondents $(n=9)$ indicating that they strongly agreed that the program was worthwhile to continue.

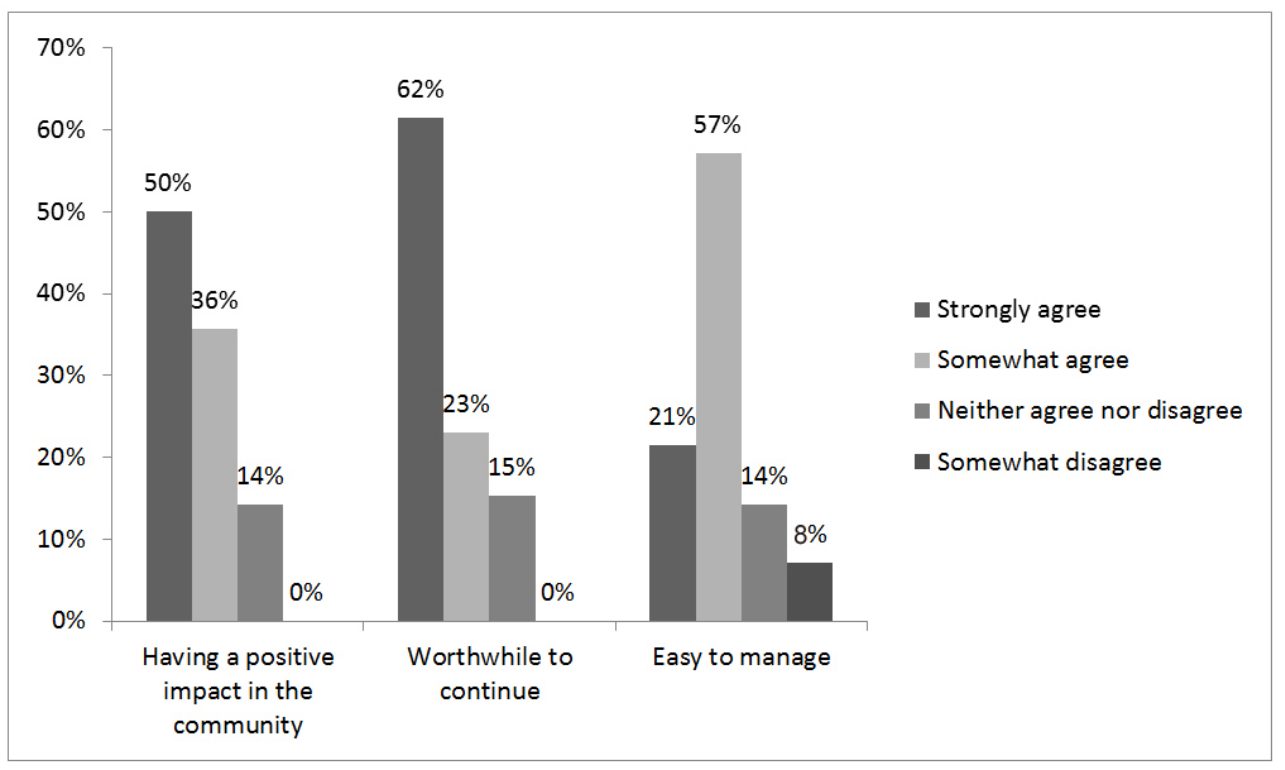

Figure 2. General satisfaction. Responses to questions of "Over the past year, please rate your organization's partnership with NCC." $\mathrm{n}=14$ NCC partner organizations

\section{Discussion}

Nursing Community Champions is a student led program that promotes and supports nursing students' engagement with a variety of community-based initiatives. Given the value of student involvement in the community setting, learning how community organizations benefit from student participation is useful in furthering collaboration. The survey described here revealed that, "improving existing health-related services [in] the community", and "strengthening the community's relationship with the University" were viewed as most important motivating factors. These findings are consistent with prior literature related to the motivations and benefits of an academic community partnership, that found the importance of increased assistance to community organizations in the form of labor and resources. ${ }^{[6,10]}$ The benefit of providing new health-related services to the community also ranked favorably on this survey, underscoring that student nurses have the power to introduce new health practices and contribute meaningfully in community settings. A major theme reiterated in our study, and found among other academic community partnerships, is the concept of sharing, defined in a descriptive case study ${ }^{[12]}$ as a, "giving of resources, advice, information and connections between participants through- out the [academic community partnership]." This mutual exchange of resources and labor is critical and a fundamental factor in creating successful academic-community partnerships.

Despite the benefits of student participation, this survey noted challenges in academic community partnerships were also prevalent. Thirty-eight percent of respondents cited student time constraints as a "very great or great challenge" of participating in the NCC program. Another challenge was the time constraints of staff and variations in priorities between staff and students, with $21 \%$ of respondents indicating it as a "great or very great challenge" to participation in the NCC program. The challenge of student nurses balancing difficult academic schedules can have a toll on community engagement. This study confirmed previous studies that suggested community partners felt most frustrated by student time constraints, lack of commitment and inconsistencies in scheduling. ${ }^{[1,4,6,13]}$ Mandatory hours were also seen as a burden by some community partners, who felt that students became motivated to meet their hourly "community service" requirements, rather than being truly invested in the community organization. ${ }^{[1]}$ Our survey data were consistent with these general themes and ranked time constraints of students 
among the biggest challenge that community organizations faced.

Despite the complexity of the community partners' relationship with the University, the overarching impression was positive and reflected the growing impact that nursing students had in being positive agents of change in NCC sites. Almost all of the respondents "strongly agree" or "somewhat agree" that the partnership was worthwhile to continue, underscoring the community's desire to not only remain engaged with service learning opportunities with students, but also to further collaboration. This finding is encouraging for $\mathrm{NCC}$ as it demonstrated that efforts to engage nursing students through various initiatives at community sites have not been without merit. Similarly, the findings suggest that for community partners, the benefits of strengthening relations with the school and providing new health related services to community members outweigh the challenges of time constraints and differing student and organization priorities.

Although these study findings are valuable, several limitations exist. The sample size for this study was relatively small, which may limit applicability to the larger pool of community organizations. Selection bias may also have been present, as the $78 \%$ of NCC community partners who chose to respond to the survey may present stronger opinions than those who chose not to respond. In addition, this survey assessed a limited number of predetermined themes based on prior literature; a more in-depth survey could have yielded other themes. Prior more comprehensive studies examined the perspective of community organizations on the relationship between social issues (poverty, race, mental illness, etc.) and how nursing students tackled those issues in the community space, ${ }^{[1,6,10]}$ which were topics not fully explored in our survey.

\section{Conclusion}

Overall, the findings from this study supported existing literature regarding the perspectives of community organizations on the motivations, benefits, challenges and general satisfaction of academic-community partnerships. Building partnerships with community sites is the first step to studentcommunity engagement and service learning, but additional steps are needed to successfully sustain these partnerships while being mutually beneficial. The perspective of community partners in these partnerships plays a crucial role in sustainability, and involves both listening and responding to those involved. ${ }^{[7]}$ The Likert survey format added an accessible, measurable element of ranking so that community partners were able to prioritize issues in order to mutually strengthen the partnership. Given that academic partners supply resources and labor to bolster community health goals, university recognition of partnership challenges and areas for improvement is paramount. This feedback becomes crucial not only to sustain long term partnerships, but also to benefit short term working goals. From the perspective of the community partners as elicited through this survey, these authors learned that sharing of labor and resources to strengthen academic-community partnerships, while addressing the challenges of time constraints and communication, are important key factors to creating mutually beneficial academic community partnership.

\section{ACKNOWLEDGEMENTS}

We thank our community partners Puentes de Salud Hacia El Futuro (Bridges Toward the Future), Hospital of the University Pennsylvania- Baby Transitions Program, Inthedance, LLC, Puentes de Salud Womens' Health Program, Up and Running Healthcare Solutions, The Free Library of Philadelphia, Spark Mentorship, Dance for Health at West Philadelphia, The Common Place, Mercy LIFE West Philadelphia, Penn Memory Center, and Sayre Recreation Center, and Netter Center for Community Partnerships University Assisted Community School at B.Comegys Elementary School and West Philadelphia High School. We also thank Richard James, Liaison Librarian for School of Nursing at the Biomedical Library, University of Pennsylvania.

\section{CONFLICTS OF INTEREST Disclosure}

The authors declare that there is no conflict of interest.

\section{REFERENCES}

[1] Sandy M, Holland BA. Different worlds and common ground: Com munity partner perspectives on campus-community partnerships. Michigan Journal of Community Service Learning. 2006; 13(1) 30-43.

[2] Wright KN, Williams P, Wright S, et al. Ties that bind: Creating and sustaining community-academic partnerships. Gateways: International Journal of Community Research and Engagement. 2011; 4:
83-99. https://doi.org/10.5130/ijcre.v4i0.1784

[3] Wolff M, Maurana CA. Building effective community-academic partnerships to improve health: a qualitative study of perspectives from communities. Academic Medicine. 2001; 76(2): 166-172. PMid:11158838 https ://doi.org/10.1097/00001888-20010 2000-00016

[4] Tryon E, Stoecker R. The unheard voices: Community organizations and service-learning. Journal of Higher Education Outreach and 
Engagement. 2008; 12(3): 47-60.

[5] Gazley B, Littlepage L, Bennett TA. What about the host agency? Nonprofit perspectives on community-based student learning and volunteering. Nonprofit and Voluntary Sector Quarterly. 2012; 41(6): 1029-1050. https://doi.org/10.1177/0899764012438698

[6] Worrall L. Asking the community: A case study of community partner perspectives. Michigan Journal of Community Service Learning. 2007; 14(1): 5-17.

[7] Cronley C, Madden E, Davis JB. Making service-learning partnerships work: Listening and responding to community partners. Journal of Community Practice. 2015; 23(2): 274-289. https: //doi.org/10.1080/10705422.2015.1027801

[8] Simmons VN, Klasko LB, Fleming K, et al. Participatory evaluation of a community-academic partnership to inform capacity-building and sustainability. Evaluation and Program Planning. 2015; 52: 19-26. PMid:25863014 https://doi.org/10.1016/j.evalprogplan .2015 .03 .005

[9] Mintz SR, Low CA, Mccurry IJ, et al. The Community Champions Program at the University of Pennsylvania School of Nurs- ing. Journal of Nursing Education and Practice. 2017; 7(8): 47. https://doi.org/10.5430/jnep.v7n8p46

[10] Blouin DD, Perry EM. Whom does service learning really serve? Community-based organizations' perspectives on service learning. Teaching Sociology. 2009; 37(2): 120-135. https ://doi.org/10 $.1177 / 0092055 \times 0903700201$

[11] Israel BA, Parker EA, Rowe Z, et al. Community-based participatory research: lessons learned from the Centers for Children's Environmental Health and Disease Prevention Research. Environmental Health Perspectives. 2005; 113(10): 1463-1471. PMid:16203263 https://doi.org/10.1289/ehp.7675

[12] Mayer K, Braband B, Killen T. Exploring collaboration in a community-academic partnership. Public Health Nursing. 2017; 34(6): 541-546. PMid:28762550 https://doi.org/10.1111/ph n. 12346

[13] Caron RM, Ulrich-Schad JD, Lafferty C. Academic-Community Partnerships: Effectiveness Evaluated Beyond the Ivory Walls. Journal of Community Engagement \& Scholarship. 2015; 8(1). 